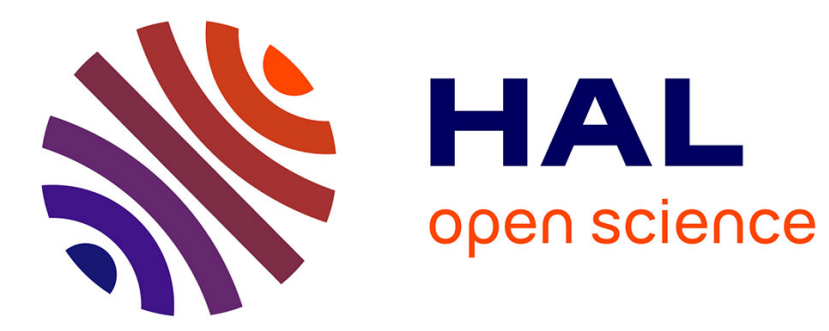

\title{
Tool-life and wear mechanisms of CBN tools in machining of Inconel 718
}

Jean-Philippe Costes, Yoann Guillet, Gérard Poulachon, Michel Dessoly

\section{To cite this version:}

Jean-Philippe Costes, Yoann Guillet, Gérard Poulachon, Michel Dessoly. Tool-life and wear mechanisms of CBN tools in machining of Inconel 718. International Journal of Machine Tools and Manufacture, 2007, 7-8, pp.1081-1087. 10.1016/j.ijmachtools.2006.09.031 . hal-01088213

\section{HAL Id: hal-01088213 \\ https://hal.science/hal-01088213}

Submitted on 13 Jan 2015

HAL is a multi-disciplinary open access archive for the deposit and dissemination of scientific research documents, whether they are published or not. The documents may come from teaching and research institutions in France or abroad, or from public or private research centers.
L'archive ouverte pluridisciplinaire HAL, est destinée au dépôt et à la diffusion de documents scientifiques de niveau recherche, publiés ou non, émanant des établissements d'enseignement et de recherche français ou étrangers, des laboratoires publics ou privés. 


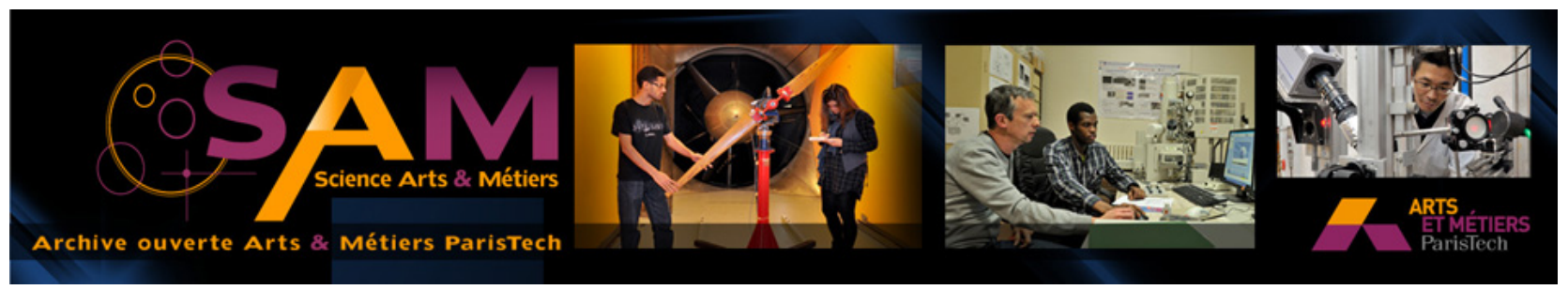

Science Arts \& Métiers (SAM)

is an open access repository that collects the work of Arts et Métiers ParisTech researchers and makes it freely available over the web where possible.

This is an author-deposited version published in: http://sam.ensam.eu

Handle ID: .http://hdl.handle.net/10985/9006

\section{To cite this version :}

Jean-Philippe COSTES, Yoann GUILLET, Gérard POULACHON, Michel DESSOLY - Tool-life and wear mechanisms of CBN tools in machining of Inconel 718 - International Journal of Machine Tools and Manufacture - Vol. 7-8, p.1081-1087 - 2007 


\title{
Tool-life and wear mechanisms of CBN tools in machining of Inconel 718
}

\author{
J.P. Costes*, Y. Guillet, G. Poulachon, M. Dessoly \\ Ecole Nationale Supe'rieure des Arts et Me'tiers, ENSAM, LaBoMap, Rue Porte de Paris, 71250 Cluny, \\ France
}

\begin{abstract}
The demand for increasing productivity when machining heat resistant alloys has resulted in the use of new tool materials such as cubic boron nitride $(\mathrm{CBN})$ or ceramics. However, $\mathrm{CBN}$ tools are mostly used by the automotive industry in hard turning, and the wear of those tools is not sufficiently known in aerospace materials. In addition, the grade of these tools is not optimized for superalloys due to these being a small part of the market, although expanding (at $20 \%$ a year). So this investigation has been conducted to show which grade is optimal and what the wear mechanisms are during finishing operations of Inconel 718. It is shown that a low CBN content with a ceramic binder and small grains gives the best results. The wear mechanisms on the rake and flank faces were investigated. Through SEM observations and chemical analysis of the tested inserts, it is shown that the dominant wear mechanisms are adhesion and diffusion due to chemical affinity between elements from workpiece and insert.
\end{abstract}

Keywords: CBN; Inconel 718; Tool wear; Diffusion; Turning

\section{Introduction}

Ni-based superalloys such as Inconel 718 are extensively used in the aerospace industry, especially in the high temperature flow area of engines, because of their excellent mechanical resistances to high temperature and corrosion.

Nowadays, finishing operations are still performed with carbide tools with low cutting speeds (around $40 \mathrm{~m} / \mathrm{min}$, tool-life around $30 \mathrm{~min}$ ). The result is that the productivity is low and in consequence the parts are very expensive. So there is a real demand to increase the productivity and new types of tools able to machine at higher cutting performances are needed.

However, the mechanics of high speed machining Inconel 718 is not sufficiently understood yet for industrial applications and Dudzinski et al. [1] explain its poor machinability:

\footnotetext{
*Corresponding author. Tel.: + 333855953 58; fax: + 33385595370 .

E-mail addresses: jean-philippe.costes@cluny.ensam.fr (J.P. Costes), yoann.guillet@gadz.org (Y. Guillet), gerard.poulachon@cluny.ensam.fr (G. Poulachon), michel.dessoly@cluny.ensam.fr (M. Dessoly).
}

- This material keeps its mechanical properties at high temperature.

- Carbides (MC) included in the material increase greatly the abrasive wear.

- Low thermal conductivity leads to high temperature during machining.

- Nickel-based alloys have a chemical affinity giving diffusion wear.

- Cutting forces are quite high during the machining.

This tool material is one of the hardest known after diamond. It is a super abrasive material and has a cubic atomic structure, like diamond. Its main characteristics are its grain size, its percentage of CBN and its type of binder.

During the operation, the cutting edge experiences high cutting temperatures and cutting forces. Harris et al. [2] showed that depending on the composition, the hardness of CBN insert changes with temperature. Harris showed that a CBN insert has the same hardness $(12.5 \mathrm{GPa}$ at $1250 \mathrm{~K})$ for $90 \%$ of $\mathrm{CBN}$ (binder $\mathrm{AlN}$ and $\mathrm{AlB}_{2}$, grain size of $15 \mu \mathrm{m}$ ) and for $45 \% \mathrm{CBN}$ (binder with TiN and $\mathrm{Al}$ and grain size smaller than $1 \mu \mathrm{m}$ ). So the CBN content is not 
the only characteristic for its hardness. Moreover, by comparison, at the same temperature $(1250 \mathrm{~K})$, he showed that an insert with $50 \%$ of $\mathrm{CBN}(10.5 \mathrm{GPa})$, is harder than one with $80 \%(9.5 \mathrm{GPa})$ of CBN. Yet they have the same binder, but the $80 \%$ insert has bigger grains. Thus, the grain size is also an important parameter in the hardness of the tool material, as well as the binder. It is the correct combination of these three factors that gives the highest hardness.

Research has been undertaken on CBN machining of Inconel 718. In the nickel-based alloys, Ezugwu et al. [3] found crater wear on the rake face, flank wear and chipping of the edge. In another study made on CBN machining titanium alloys, these types of wear also were shown by Ezugwu [4]. When CBN was used for machining mold steel, Farhat [5] identified the same phenomena for very high cutting speed $(1000 \mathrm{~m} / \mathrm{min})$. Poulachon et al. [6] worked on hard alloy steel machined by CBN and studied crater wear showing that the appearance of a third-body [7] could induce chemical wear in the tool. Wear mechanisms of CBN tools, machining M2 steel, have been presented by Hong [8] as chemical wear due to the diffusion of elements from the work material and the establishment of new chemical products. Brandt et al. [9] tried to explain these chemical reactions when ceramic tools are machining Inconel 718; he found that ceramic inserts with nitrogen have a better chemical wear resistance. So, among the various workpiece material-tool pairs CBN-Inconel 718, CBN-mold steel, CBN-titanium alloys, CBN-hardened steels or ceramic-Inconel 718, the chemical elements reacting together can be: $\mathrm{Fe}, \mathrm{Ni}, \mathrm{Ti}, \mathrm{Cr}, \mathrm{Al}, \mathrm{Nb}, \mathrm{B}$ and $\mathrm{N}$ from the work material and the insert.

This study has been performed in order to find the best combination between the three main characteristics of CBN composition (binder, grain size, $\mathrm{CBN}$ content) for the finishing operation in the machining of Inconel 718. In addition, as the wear mechanisms are complex, the wear of CBN tools when machining Inconel 718 is examined.

\section{Investigation on tool binder and CBN content effects on tool-life}

\subsection{Experimental procedure}

A first set of cutting test has been conducted with 27 CBN inserts including various kinds of binders, CBN contents and grain sizes.

Two types of round inserts (RNGN090300E) have been used:

- CBN solid.

- CBN full face brazed on a WC substrate. The CBN layer height was $0.7 \mathrm{~mm}$.

The tool holder was CRSNR 2525M09. The CBN content of tested inserts was varying in the range of $50-95 \%$ and the grain size in the range of $2-8 \mu \mathrm{m}$.
Table 1

Chemical composition of Inconel 718 (in \% of mass)

\begin{tabular}{llllll}
\hline Inconel 718: $\mathrm{NC}$ 19 Fe Nb & & & \\
\hline $\mathrm{Ni}$ & $\mathrm{Cr}$ & $\mathrm{Co}$ & $\mathrm{Mo}$ & $\mathrm{Al}$ & $\mathrm{C}$ \\
$50-55$ & $17-21$ & $1 \mathrm{max}$ & $2.8-3.3$ & $0.3-0.7$ & $0.02-0.08$ \\
$\mathrm{Si}$ & $\mathrm{Mn}$ & $\mathrm{Fe}$ & $\mathrm{Cu}$ & $\mathrm{S}$ & $\mathrm{P}$ \\
$0.35 \max$ & $0.35 \max$ & $\mathrm{rest}$ & $0.2 \max$ & $0.015 \max$ & $0.015 \max$ \\
$\mathrm{B}$ & $\mathrm{Nb}+\mathrm{Ta}$ & $\mathrm{Ti}$ & & & \\
$0.006 \max$ & $4.8-5.5$ & $0.7-1.15$ & & & \\
\hline
\end{tabular}

The operations were carried out on a $\mathrm{CNC}$ lathe. Waterbased oil coolant ( $6 \%$ of oil) was used in all cutting tests. The material was solution treated and aged Inconel 718 with a hardness of 40-45 HRc. The chemical composition is shown in Table 1. The workpiece was in the form of round bar of $160 \mathrm{~mm}$ diameter and $160 \mathrm{~mm}$ length. For each type of insert, the cutting test was repeated twice.

Based on typical conditions found in finishing operations, the depth of cut and the feed rate were fixed:

- Feed rate, $f=0.2 \mathrm{~mm} / \mathrm{rev}$.

- Depth of cut, $a_{\mathrm{p}}=0.3 \mathrm{~mm}$.

According to the French standard (tool material pair) [10], preliminary experiments have been carried out by the authors to find the suitable range of cutting speeds; six cutting speeds from 50 to $500 \mathrm{~m} / \mathrm{min}$ have been tested for a $65 \% \mathrm{CBN}$ insert with a TiN binder and $2 \mu \mathrm{m}$ grain size. The specific cutting force has been measured for each cutting speed. From those results, we concluded that the suitable range of cutting speeds is from 200 to $450 \mathrm{~m} / \mathrm{min}$. Therefore, a $200 \mathrm{~m} / \mathrm{min}$ cutting speed has been chosen for all the following tests.

\subsection{Results}

Fig. 1 shows the effects of the CBN content and the type of binder on tool-life. The tool was considered worn when the flank wear $\left(V_{\mathrm{B}}\right)$ reached $0.3 \mathrm{~mm}$. The type of binder is given by the tool suppliers. In Fig. 1, a binder called ceramic is made with $\mathrm{Al}_{2} \mathrm{O}_{3}$, nitride and carbide. Tool suppliers differentiate between pure ceramic $\left(\mathrm{Al}_{2} \mathrm{O}_{3}\right)$ and mixed ceramic $\left(\mathrm{Al}_{2} \mathrm{O}_{3}\right)$ with a metallic phase ( $\mathrm{TiC}$ or $\left.\mathrm{TiN}\right)$. But some others have a composite designation: mixed or metallic ( $\mathrm{Ti}, \mathrm{Al}, \mathrm{W}, \mathrm{Co}, \ldots)$. So a composite with mixed ceramic and metallic can be called ceramic. References depend on the tool suppliers.

As shown in Fig. 1, a general difference in life is noticeable in tool with CBN content below $65 \%$ and those with CBN content above $80 \%$ : tool life decreases from 9.6 to $2.8 \mathrm{~min}$ on average. It is definite that longest tool-lives are obtained with a low CBN content (below 65\%). With CBN content above $80 \%$, tool life is $2.8 \mathrm{~min}$ on average. Moreover, Fig. 1 shows that the binder appears to be a 
main parameter affecting tool-life. Inserts with ceramic binders ( $\mathrm{TiC}$, TiN or $\mathrm{Ti}$ ) with $\mathrm{CBN}$ contents below $65 \%$ have long lives. A combination of ceramic binder and high CBN content above $80 \%$ result in a low tool-life. A content of CBN below $65 \%$ and a binder with no Ti has not been tested, but binders with and without $\mathrm{Ti}$ give the same results in inserts with a high content of CBN. In addition, a binder with low CBN content is made, usually, with Ti and

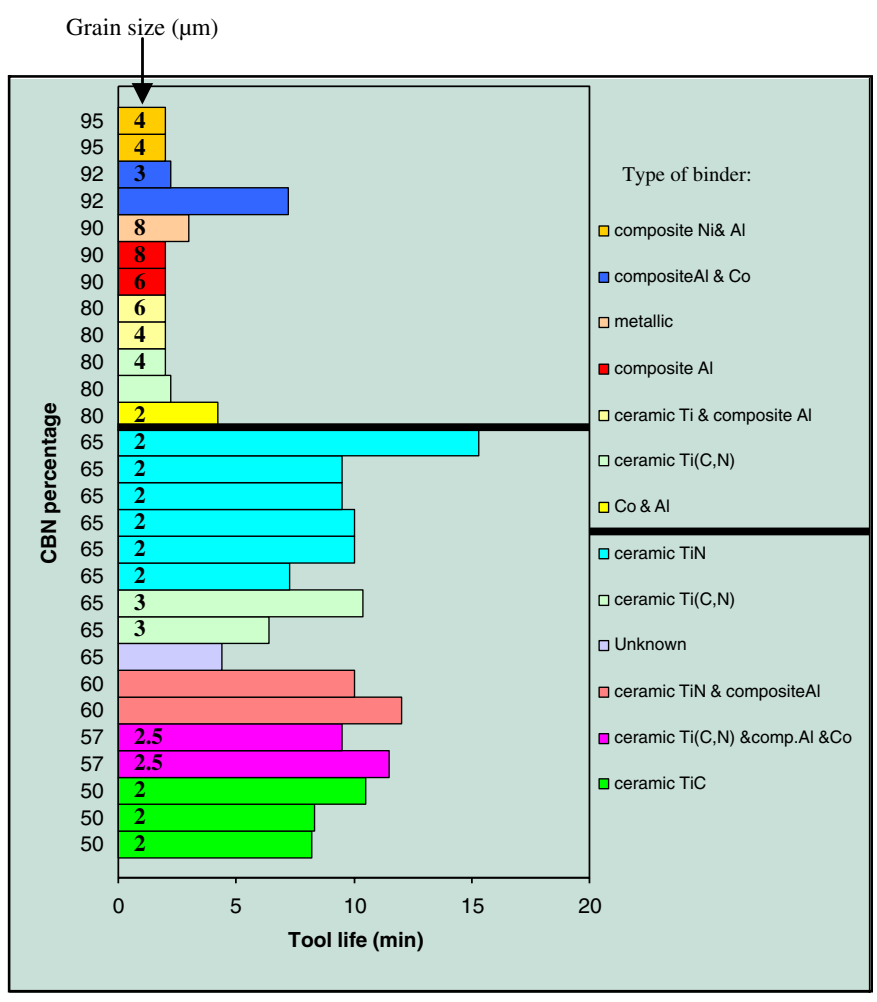

Fig. 1. Effect of $\mathrm{CBN}$ content and binder on the tool-life (wear criterion $\left.V_{\mathrm{B}}=0.3 \mathrm{~mm}\right)$. with a composite of $\mathrm{Al}$ or $\mathrm{Al}$ and $\mathrm{Co}$. This binder is called ceramic.

Through studies made on the coating of carbide tools, by Jindal et al. [11], it is interesting to note that the best coating (PVD), in terms of tool-life when machining Inconel 718, is TiAlN, compared to TiN and TiCN. Here, these two latter products are used as binders for CBN inserts.

Fig. 1 includes results for grain size between 2 and $8 \mu \mathrm{m}$. The longest tool-lives are obtained for any content with small grain sizes. But, since the grain size variation for CBN content less than $80 \%$ is small, it is hard to conclude about a significant grain size effect.

\subsection{Study on cutting speed effect on wear}

A new series of cutting tests were conducted with dedicated CBN tools; From the results presented in the previous section, the CBN content was kept under $65 \%$ and the grain size maintained at $1 \mu \mathrm{m}$, with $\mathrm{TiC}$ binder composition. Three different contents of $\mathrm{CBN}$ were tested: $30 \%, 45 \%$ and $60 \%$ with three different cutting speeds: 250,350 and $450 \mathrm{~m} / \mathrm{min}$. Feed rate was $0.2 \mathrm{~mm} / \mathrm{rev}$ and depth of cut $0.5 \mathrm{~mm}$. The flank wear was measured after 45 and $300 \mathrm{~s}$. These times may seem to be low, but a $350 \mathrm{~m} /$ min cutting speed yields to $1750 \mathrm{~m}$ length of cut.

Analyses of the tool wear patterns are summarized in Table 2. The $30 \%$ CBN insert gives very poor results in terms of tool damage. The insert most adapted to Inconel 718 seems to be the one with $45 \% \mathrm{CBN}$. Its behavior is similar to the one with $60 \%$ of CBN, which seems to be less adapted at higher cutting speeds. Nevertheless, high cutting speeds (around $450 \mathrm{~m} / \mathrm{min}$ ) are not appropriate, since even at $45 \mathrm{~s}$, no insert has a progressive wear.

Nevertheless, these analyses must be completed with cutting forces measurements. A three component piezoelectric

Table 2

Wear observations for small grained inserts

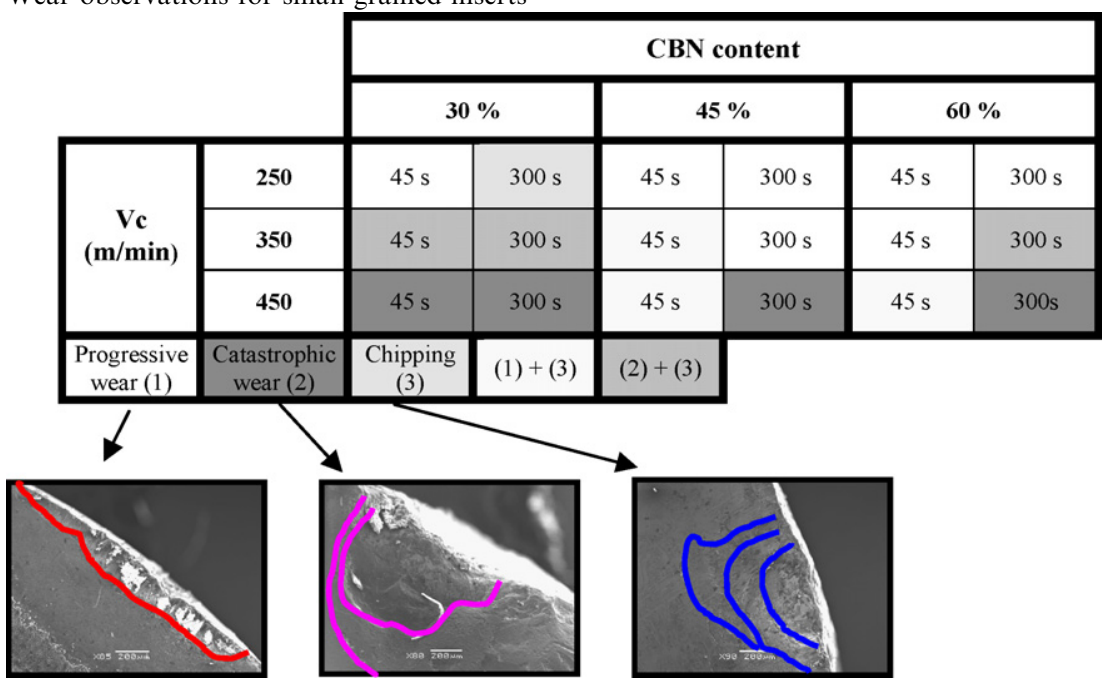


dynamometer was used in order to measure the cutting forces in longitudinal turning tests. Fig. 2 compares the three forces components together $\left(F_{\mathrm{p}}=\right.$ thrust force, $F_{\mathrm{c}}=$ cutting force, $F_{\mathrm{f}}=$ feed force) and it is shown that the thrust force is always the highest one. Fig. 3 summarizes the thrust force levels (wide columns) with the corresponding flank wears (narrow columns) for the three inserts at 250 and $350 \mathrm{~m} / \mathrm{min}$ cutting speed after $300 \mathrm{~s}$ machining. It is noticeable that the trend of the progression of wear with cutting speed is similar to that of the trend of the cutting forces.

For the $30 \%$ CBN content and $350 \mathrm{~m} / \mathrm{min}$ cutting speed, the insert is completely worn. This does not allow flank wear to be measured. That is why no flank wear value appears in Fig. 3 for this insert at $350 \mathrm{~m} / \mathrm{min}$. This same insert shows cutting force value twice higher at $350 \mathrm{~m} / \mathrm{min}$ than the two other inserts at 250 and $350 \mathrm{~m} / \mathrm{min}$. The rapid damage of the $30 \%$ CBN content insert at $V_{\mathrm{c}}=350 \mathrm{~m} / \mathrm{min}$ is outstanding. This has to be correlated to the catastrophic wear encountered for this insert at $350 \mathrm{~m} / \mathrm{min}$. For $45 \%$

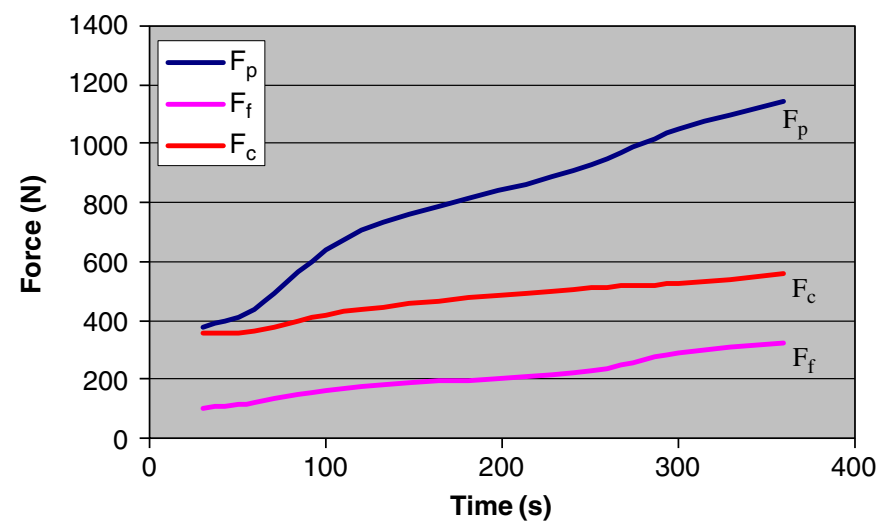

Fig. 2. Evolution of the three force components $\left(V_{\mathrm{c}}=350 \mathrm{~m} / \mathrm{min}\right.$, $a_{\mathrm{p}}=0.5 \mathrm{~mm}, f=0.2 \mathrm{~mm} / \mathrm{rev}$ ) for $45 \% \mathrm{CBN}$ insert, $1 \mu \mathrm{m}$ grain size, TiN coating.

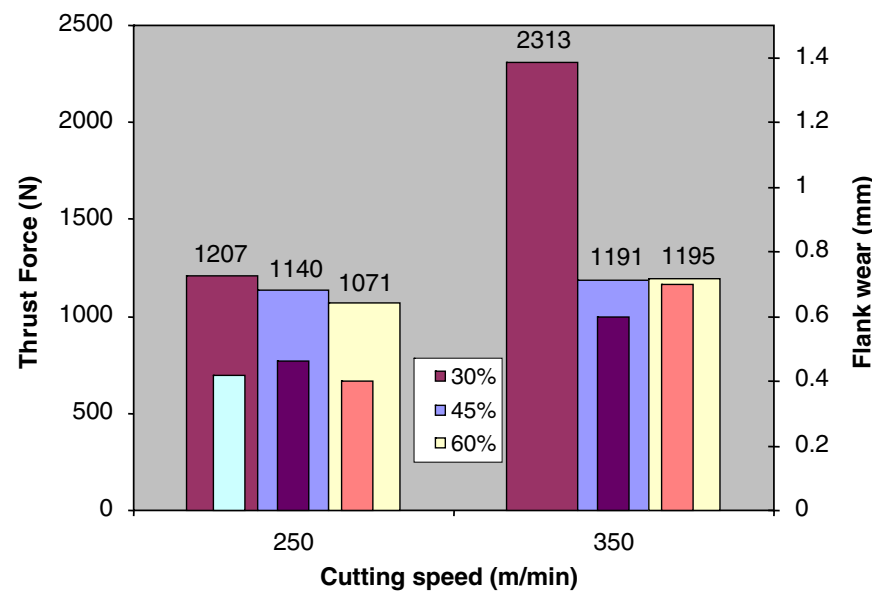

Fig. 3. Evolution of flank wear and thrust force against the cutting speed after 5 min machining for 3 inserts with various $\mathrm{CBN}$ contents. Forces $=$ wide columns; Flank wear $=$ narrow columns. This figure gives no wear value for the $30 \% \mathrm{CBN}$ content insert and a $350 \mathrm{~m} / \mathrm{min}$ cutting speed since the CBN completely disappeared. and $60 \% \mathrm{CBN}$ content inserts, it is outstanding that the cutting speed has a strong effect on flank wear whereas cutting forces remain almost constant. Secondly, for these same two inserts, we conclude that the increase of flank wear does not yield to a significant force increase.

\subsection{Wear mechanisms of CBN tools}

\subsubsection{Evolution of tool wear}

The goal of this section is to observe the evolution of the tool damage during machining in order to characterize the wear mechanisms (abrasion, diffusion, adhesion, oxidation,...). The $\mathrm{CBN}$ tool used in this instance is a round full-face insert with $60 \%$ of CBN, $2 \mu \mathrm{m}$ grain size and a TiC binder. A new series of cutting tests was conducted with the following cutting conditions: $a_{\mathrm{p}}=0.5 \mathrm{~mm}, V_{\mathrm{c}}=250 \mathrm{~m} / \mathrm{min}$ and $f=0.2 \mathrm{~mm} / \mathrm{rev}$.

The tool insert was observed at $T_{1}=45 \mathrm{~s}$ of machining, $T_{2}=3 \mathrm{~min}, 45 \mathrm{~s}$ and $T_{3}=6 \mathrm{~min}$ by SEM analysis. $T_{1}$ represents the beginning of the wear after the running-in time, $T_{2}$ is half of the tool-life and $T_{3}$ represents the end of the tool-life. As the insert is round, the three wear measurements were obtained from the same insert by indexing it as shown in Fig. 4.

Figs. 5(a)-(c) show the wear patterns at $T_{1}, T_{2}, T_{3}$ on the flank face and at the edge and the wear evolution is:

First, a notch wear is created in the depth of cut region and the flank wear is almost zero. The workpiece material forms a deposit on the rake face.

Then, at $T_{2}$, the flank wear has grown, hiding the notch wear. The rake face presents a larger amount of deposit.

Finally at $T_{3}$, the impact of the heat, due to the process, can be noticed on the rake face of the insert from the edge to the center. Moreover a lot of deposit is present on the flank and rake faces.

Figs. 6(a) and (b) show general and magnified pictures of the worn areas of the rake face and the edge at time $T_{1}$ and

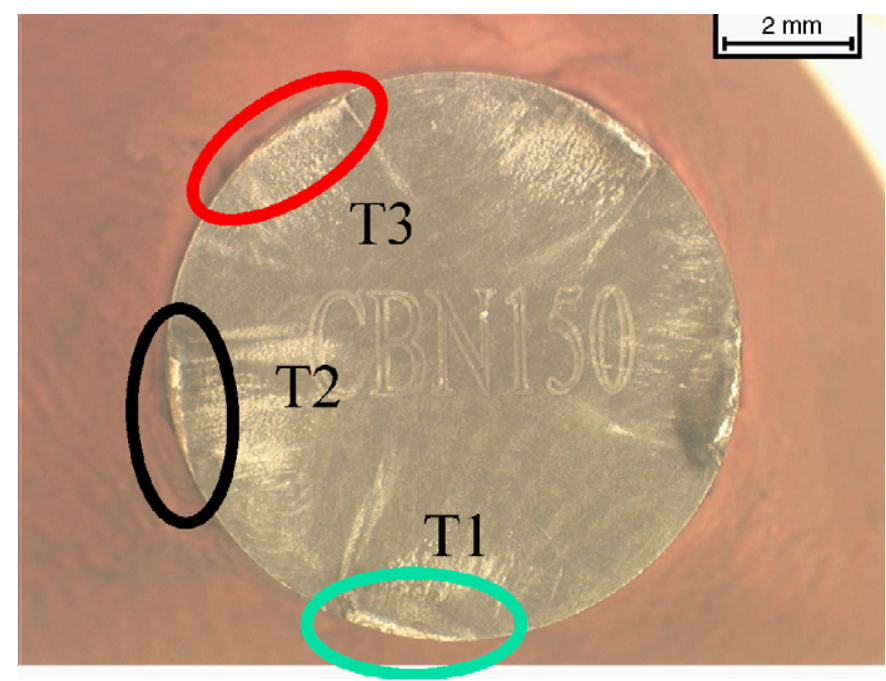

Fig. 4. Insert with the three wear regions at $T_{1}, T_{2}, T_{3}$. 
$T_{3}$. At these two times, EDX analyses were conducted on the worn regions. The graphs on the side present the chemical contents for several elements measured along the line plotted on the magnified picture.

The EDX analysis shows that a reposition of chemical elements is set within the deposit, on the rake face of the tool. The elements $\mathrm{Al}$ and $\mathrm{Ti}$ come from the binder of the insert and $\mathrm{Cr}, \mathrm{Fe}, \mathrm{Nb}$, and $\mathrm{Ni}$ from the workpiece material. There is a query with magnesium, since it does not come from the Inconel 718, the tool insert and an EDX analysis on the lubricant does not show this chemical element. It may be a residue due to the process used to make CBN inserts.

From the edge to the center of the insert, the distribution is as follows: an area with $\mathrm{Nb}$ and $\mathrm{Ti}$, then a band of $\mathrm{Al}$ and $\mathrm{Mg}$ and further, a layer of the workpiece material. At $6 \mathrm{~min}$ of machining, the separation between chemical elements is more pronounced. Chemical elements move and may react with chemical elements of the $\mathrm{CBN}$ insert
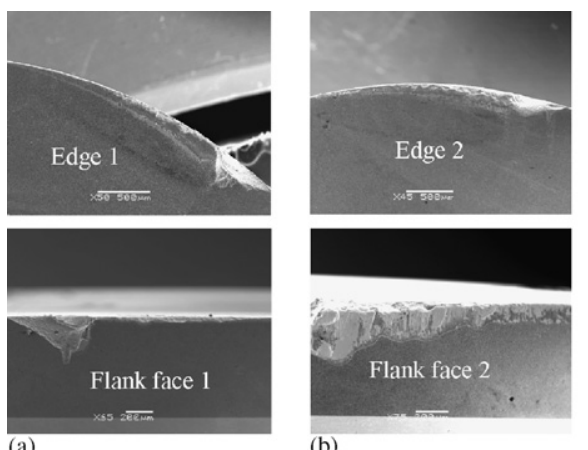

(b)

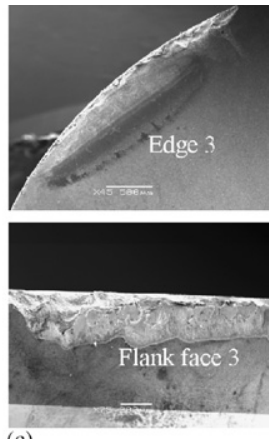

(c)

Fig. 5. Observation of the rake and flank faces at the SEM: (a) $T_{1}=45 \mathrm{~s}$; (b) $T_{2}=3 \mathrm{~min}, 45 \mathrm{~s}$; (c) $T_{3}=6 \mathrm{~min}$

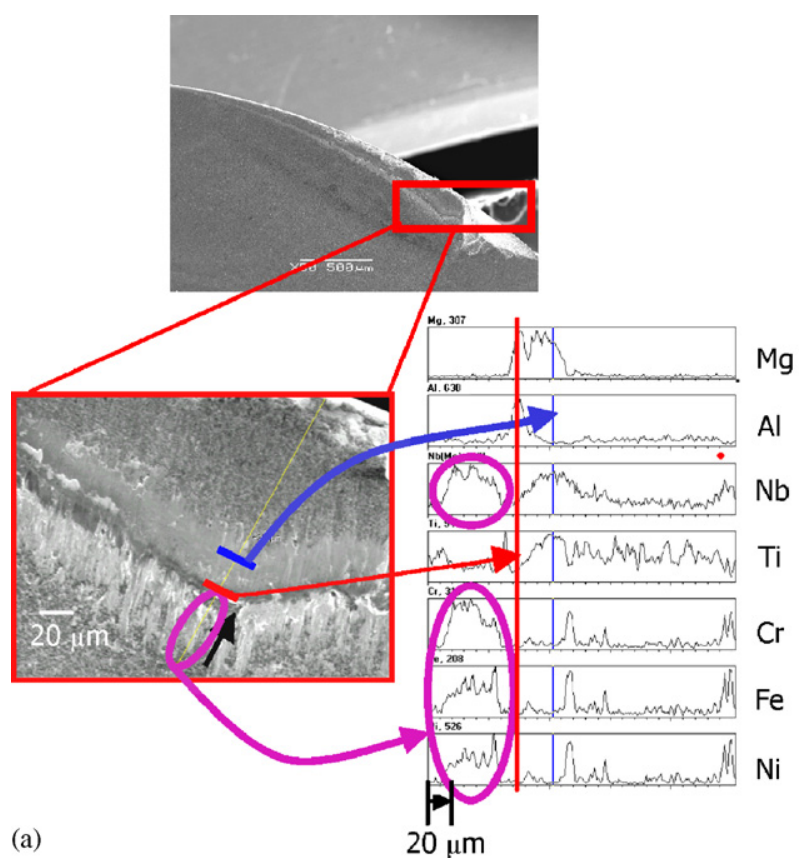

giving the location seen in Fig. 6(b). And even chemical element like iron is separated at $6 \mathrm{~min}$, whereas it was combined with chromium and nickel. As some elements are from the workpiece and others from the tool material, diffusion gives chemical reactions modifying the properties of the thin layer.

This part of the study shows that there is a diffusion of $\mathrm{Nb}, \mathrm{Cr}, \mathrm{Fe}$ and $\mathrm{Ni}$ in the insert. And this is reinforced by the study made by Arunachalam et al. [12]. Indeed, they have observed a mutual diffusion between the binder (with cobalt) and the workpiece material.

Moreover, this diffusion appears in different areas with chemical elements, and these areas should represent specific cutting conditions in terms of pressure and temperature.

In order to decrease diffusion, the last conditions must be different, and counteracting the effect of temperature would prevent the chemical reactions. Several systems are known: Wang et al. [13] worked on one of these processes. By using a liquid nitrogen system to cool the ceramic tool, machining Inconel 718, the forces were decreased by $30-50 \%$ and the tool-life was extended up to $170 \%$ over conventional machining. As the CBN inserts, which have the best tool-life, have a ceramic binder, the nitrogen cooling system could be helpful in increasing the CBN tool-life.

\subsubsection{Depth of diffusion}

In order to quantify the depth of diffusion of the previous chemical elements, a cross-section analyses of the insert has been made by EDX. In order to achieve this investigation, the insert was broken part-to-part at time $T_{3}$ resulting in an unaffected surface as illustrated in Figs. 7(a) and (b). Fig. 8(a) gives the EDX analysis of the broken face from the rake face surface to the inside of the CBN layer

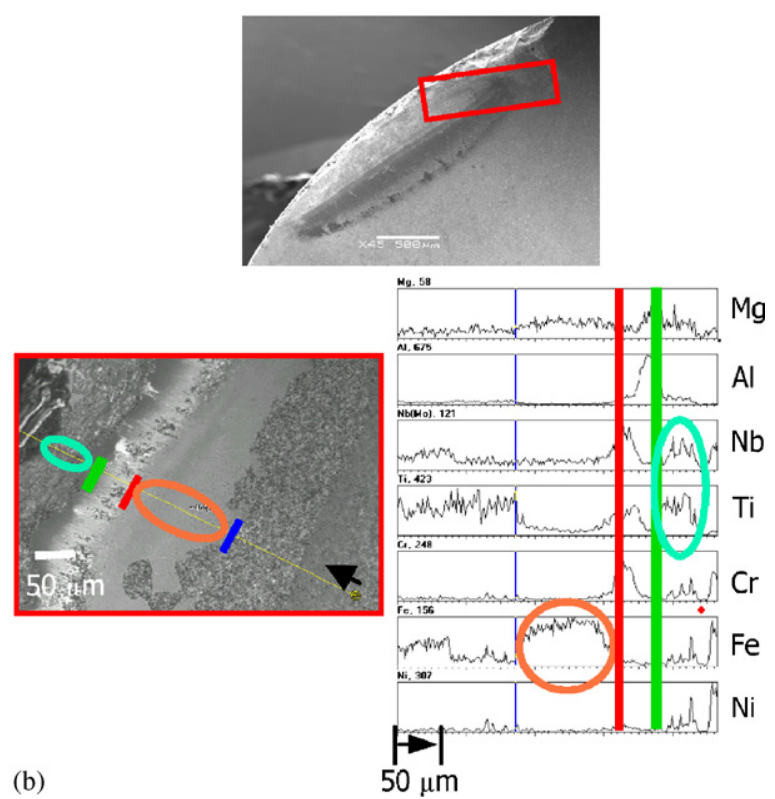

Fig. 6. EDX profile on the rake face at (a) $T_{1}=45 \mathrm{~s}$, (b) $T_{3}=6 \mathrm{~min}$ 
(EDX measurements are conducted and plotted along the yellow line). Above the line, the workpiece material is observed. The elements from Inconel 718 (Cr, Ni, Fe, Nb) seem to diffuse in the insert within a few microns.

On the flank face, some striations are observed. Fig. 8(b) shows the EDX analysis from the flank face to the inside. The profile shows the presence of firstly, chemical elements of the insert (Al, Ti), and secondly, a layer of some elements from the workpiece.

\subsubsection{Morphology and structure of the chip}

The secondary shear zone of the chip is in contact with the rake face during machining. The presence, on the tool, of chemical elements from the workpiece, comes from the chip. So the aim of this section is to see which elements are present in the secondary shear zone and its structure in order to understand the presence of new chemical elements

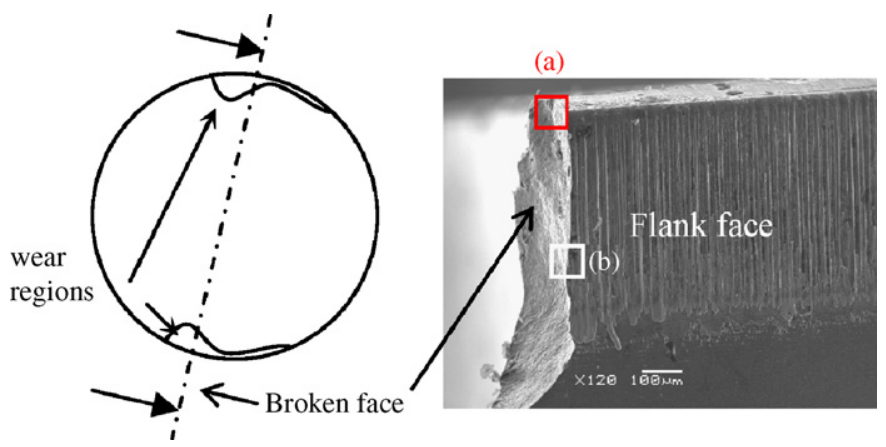

Fig. 7. Insert broken along the dashed line before SEM observation.
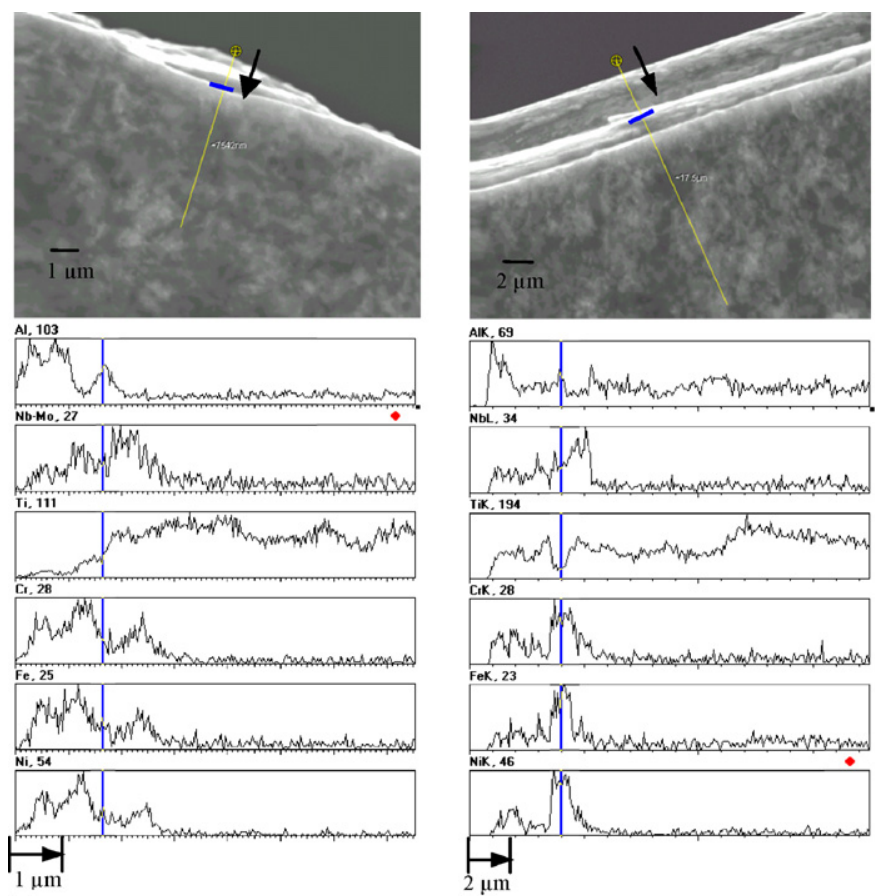

(a)

(b)

Fig. 8. EDX profiles in depth of the rake (a) and flank faces (b) view in the broken face. on the tool. A chemical etching with oxalic acid was applied to a chip to allow the study of the metal structure. The sample has been observed with SEM, as shown in Fig. 9.

The primary shear and the secondary shear zones of the chip have the same nature, without the $\delta$ phase $\left(\mathrm{Ni}_{3} \mathrm{Nb}\right)$. They are also different from the remainder of the chip, and connected. These two bands are linked and their formation during machining may appear at the same time. The high pressure and temperature conditions during machining explain this change of structure. During this change the $\delta$ phase can be restructured, loosing chemical elements like Niobium and allowing the workpiece material to spread to the tool.

An estimate of temperature can be given by numerical simulation. A study, carried out by Uhlmann et al. [14], on ceramic machining Inconel 718, shows that the maximum of temperature in the chip is on the primary and secondary shear zones at around $1000^{\circ} \mathrm{C}$. As the secondary shear zone is in contact with the rake face, this face can be at this level of temperature.

\subsubsection{Analysis of wear under the built up layer}

Through previous studies, phenomena have been shown such as adhesion of workpiece material including diffusion on the tool. Nevertheless, the state of the insert under the layer is unknown and is a main parameter in understanding the wear mechanisms. So, dissolving of metal elements has occurred. The chemical composition of the rake face is mostly with $\mathrm{Al}$ and $\mathrm{O}$, and only a little $\mathrm{Nb}, \mathrm{Ti}, \mathrm{Cr}, \mathrm{Ni}$ and $\mathrm{Fe}$ remain, due to the chemical etching. So the new precipitate made by $\mathrm{Nb}$ and $\mathrm{Ti}$ has a metal nature. If these two elements react together, the binder fails, allowing CBN

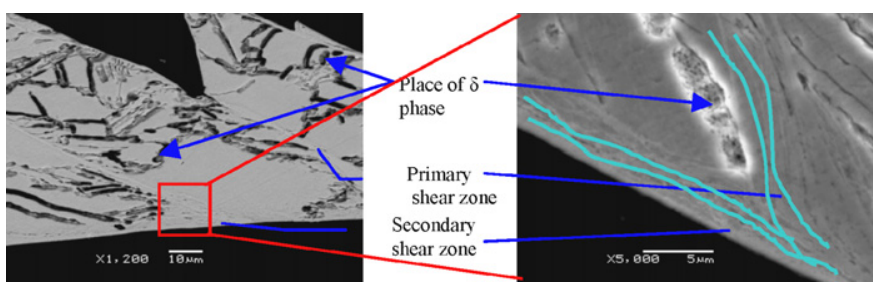

Fig. 9. SEM observation of a chip after etching.
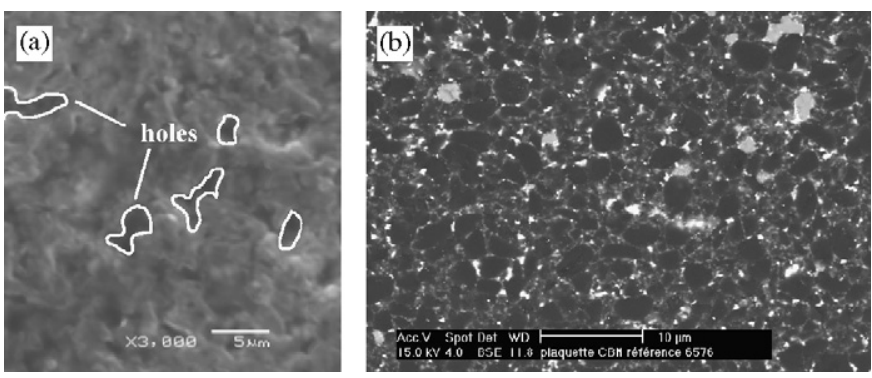

Fig. 10. Appearance of the insert on the worn rake face etched (a) and a new rake face (b). 
grains to pull out of the insert, within a layer of workpiece material, during machining. Fig. 10(a) shows the appearance of the insert under the workpiece layer. There are holes as if grains had been pulled off the binder.

\section{Conclusions}

The investigation on the grade of $\mathrm{CBN}$, shows that better wear is obtained with a content between $45 \%$ and $60 \%$ and a cutting speed between 250 and $300 \mathrm{~m} / \mathrm{min}$. Through the analyses of studies made for the wear of CBN tools, a description of the modes of degradation is given: during machining, the workpiece, under high temperatures and stresses, plasticized itself superficially, so the alloy spread on the contact area between the insert and the workpiece (rake and flank faces). As chemical elements from the two materials have a chemical affinity, some of the Inconel 718 diffuses in the insert, making new compounds with different physical characteristics. This phase is less resistant than the initial one, and the new layer is pulled out with machining mechanisms, taking with it elements from the insert (binder and $\mathrm{CBN}$ grains). This offers an almost virgin surface and a new layer can settle. This mechanism starts again periodically and very quickly. Thus, the dominant wear mechanisms of the CBN cutting tool during the cutting process are adhesion, then diffusion and finally abrasion.

The effect of grain size on tool life has not been well shown in this study since its variation within the experimental campaign is small. A further study will focus on that particular point.

\section{Acknowledgments}

The authors acknowledge the support of Snecma Moteurs for its willingness to understand and study the behavior of the inserts before industrialization of new products. Authors also thank SECO and ElementSix for their experience and support.

\section{References}

[1] D. Dudzinski, A. Devillez, A. Moufki, D. Larrouquère, V. Zerrouki, J. Vigneau, A review of development towards dry and high speed machining of Inconel 718 alloy, International Journal of Machine Tools and Manufacture 44 (2004) 439-456.

[2] T.K. Harris, E.J. Brookes, C.J. Taylor, The effect of temperature on the hardness of polycrystalline cubic boron nitride cutting tool materials, International Journal of Refractory Metals and Hard Materials 22 (2004) 105-110.

[3] E.O. Ezugwu, J. Bonney, Y. Yamane, An overview of the machinability of aeroengine alloys, Journal of Materials Processing Technology 134 (2003) 233-253.

[4] E.O. Ezugwu, R.B. Da Silva, J. Bonnet, A.R. Machado, Evaluation of performance of CBN tools when turning Ti-6Al-4V alloy with high pressure coolant supplies, International Journal of Machine Tools and Manufacture 45 (2005) 1009-1014.

[5] Z.N. Farhat, Wear mechanism of CBN cutting tool during highspeed machining of mold steel, Materials Science and Engineering A 361 (2003) 100-110.

[6] G. Poulachon, B.P. Bandyopadhyay, I.S. Jawahir, S. Pheulpin, E. Seguin, Wear behavior of $\mathrm{CBN}$ tools while turning various hardened steels, Wear 253 (2004) 302-310.

[7] Y. Berthier, Third body reality, consequence and use of the third body to solve a friction and wear problem, in: G. Stachowiack (Ed.), Wear, Materials, Mechanisms and Practice, Wiley, 2005, pp. 291-316, ISBN 0-470-01628-0.

[8] X. Hong, Wear behavior and wear mechanism of ceramic tools in machining hardened alloy steel, Wear 139 (2) (1990) 439-451.

[9] G. Brandt, A. Gerendas, M. Mikus, Wear mechanisms of ceramic cutting tools when machining ferrous and non-ferrous alloys, Journal of European Ceramic Society 6 (1990) 273-290.

[10] AFNOR Standart NF E 66-520, Couple outil-matière: Domaine de fonctionnement des outils coupants, vols. 1-6, 1994.

[11] P.C. Jindal, A.T. Santhanam, U. Schleinkofer, A.F. Shuster, Performance of PVD TiN, TiCN, and TiAlN coated cemented carbide tools in turning, International Journal of Refractory Metals and Hard Materials 17 (1999) 163-170.

[12] R.M. Arunachalam, M.A. Mannan, Performance of CBN cutting tools in facing of age hardened Inconel 718, Trans. NAMRI/SME 32 (2004) 525-532.

[13] Z.Y. Wang, K.P. Rajurkar, J. Fan, S. Lei, Y.C. Shin, G. Petrescu, Hybrid machining of Inconel 718, International Journal of Machine Tools and Manufacture 43 (2003) 1391-1396.

[14] E. Uhlmann, R. Zettier, R. Sievert, R. Clos, FE simulation of highspeed turning of Inconel 718, in: A. Moisan, G. Poulachon (Eds.), Seventh CIRP International Workshop on Modelling of Machining Operations, ENSAM Cluny, France, May 2004, pp. 67-74, ISBN 2-900781-51-5. 